Vol. 5, No. 2, 2020

\title{
CYBER-PHYSICAL SYSTEM TO HELP MOOR A SHIP
}

\author{
Andrii Grebeniak \\ Lviv Polytechnic National University, 12, Bandera Str, Lviv, 79013, Ukraine \\ Author's e-mail: andrii.v.hrebeniak@lpnu.ua
}

Submitted on 18.12.2020

(C) Grebeniak A., 2020

Abstract: A method of organizing an information cyberphysical system to assist in the mooring process has been considered in the article. It describes ways to organize the mooring of ships to the berth. The problems that occur during this operation have been listed. As the mooring process is labor-intensive and depends on the human factor, a system that will provide up-to-date real-time information to facilitate the mooring operation has been regarded. The structure and stages of development of the proposed solution have been described. The features of the selected elements have been indicated. Obtaining preliminary sensory results from two ports makes it possible to begin the next stage of system development.

Index Terms: moor, cyber-physical system, sensor unit.

\section{INTRODUCTION}

The mooring process is an important, inherent and frequently repetitive procedure in marine operation. This procedure is also responsible enough because it has certain risks to deal with. These risks are caused by the large ship inertia and relatively low stability of a ship. There are some restrictions for realization of this task. The mooring process occurs at the shore berth or it can be tied up to another ship. A mooring at the shore berth depends on the ship length. Moreover, it is also important what kind of moorage it is. It requires 2 men at the pier and some tugboats (both Ship Captain and Marine Pilot decide the quantity) for the ships up to 60 meters. Furthermore, we need at least 4 men at the pier and 2 tugboats for the ships up to 100-135 meters (Fig. 1).

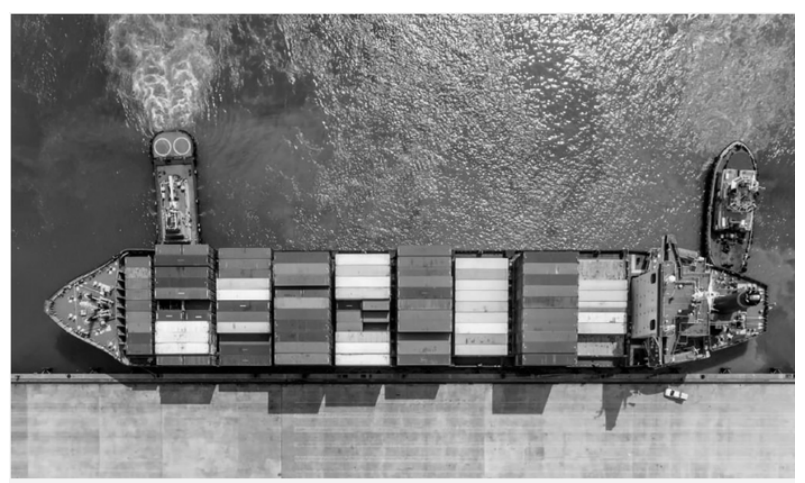

can moor a boat. In some really loaded and busy ports this procedure is organized. A Marine Pilot - the port employee who enters the ship's side and takes the responsibility for mooring a ship. He has a walkie-talkie which he uses to organize the mooring process between marine team and tug boats for successful ship mooring. For huge ships this procedure can last for hours. It is important to move the boat slowly and parallel to the side because the ship has large inertia.

Pulling up the ship proceeds using mooring ropes evenly. It is important to control the distance to the pier. To avoid damaging the hull and the pier equipment, the Baffle Mechanisms on the ship (Fig. 2) or at the pier are usually used (Fig. 3)

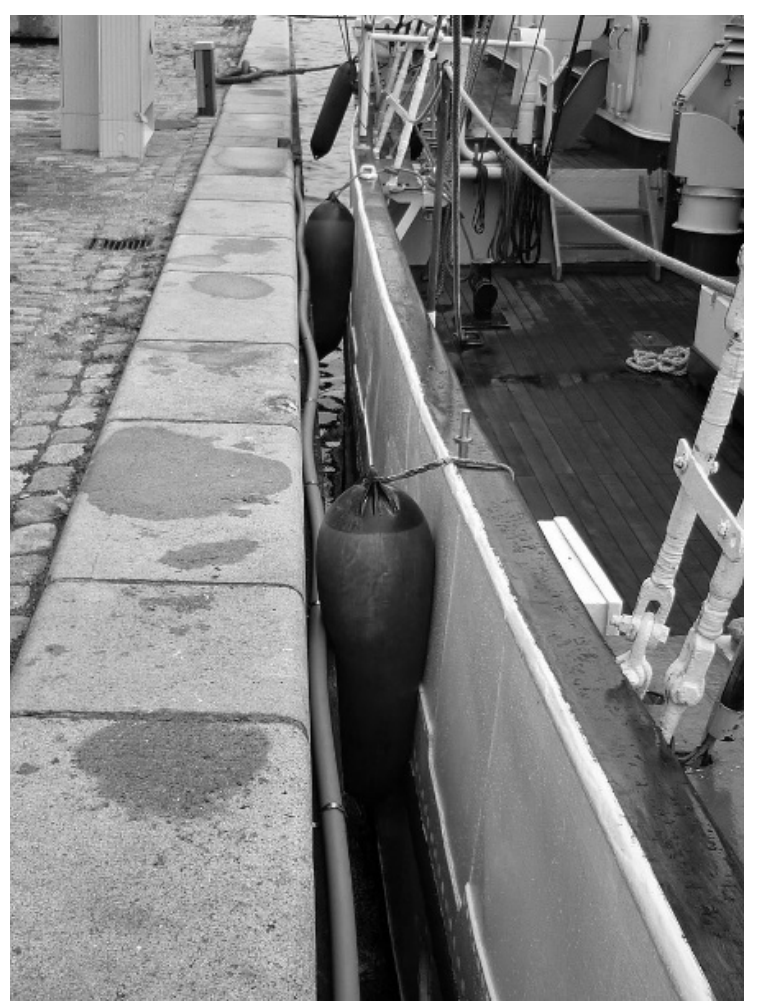

Fig. 2. The ship's Baffle Mechanisms

The mooring process takes a lot of time. Fig. 1. The mooring process using tugboats

There is supposed to be at least 10 people at the pier as well as a sufficient number of tugboats for ships more than 200 meters [1]. In some ports the marine team Consequently, it is expensive for the owner to pay for it. In some cases, the installation equipment can be damaged because the ship approaches the Baffle Mechanisms sooner than it's supposed to. As a result, the pier needs to be fixed and it takes a lot of time. 


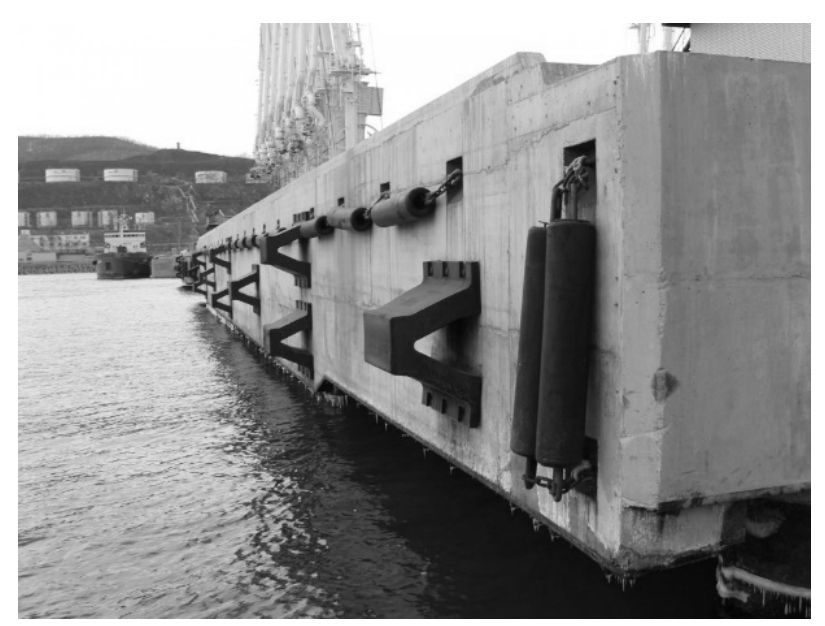

Fig. 3. The pier's Baffle Mechanisms

The success depends on the combined employees' work and the Marine Pilot experience - he runs the process. The Marine Pilot gets information about the ship's position from the group of people using walkietalkies. He gives the directions to tugboat workers.

This kind of entering the mooring is typical for all loaded ports. They try to take as little time as they can to moor it. They try to minimize loading and unloading. One way to simplify the mooring is a system called Trelleborg Automoor [2]. In other words, it looks like huge suckers (Fig. 4). The mooring process is so simplified here: a ship is brought to a safe distance and Automoor automatically pulls it up and deters the ship by The Baffle Mechanisms. Except the evident advantages for example the mooring speed - there is another problem. The cost is high, so this system is relevant only for ports with a high turnover.

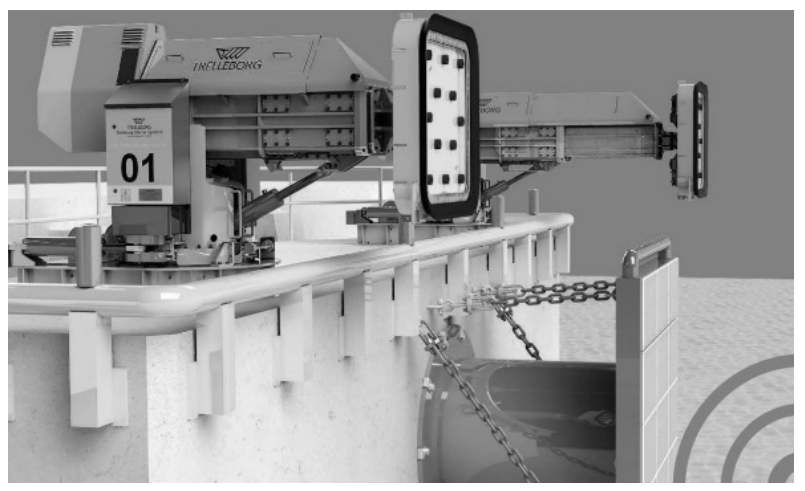

Fig. 4. The system of automatic mooring Trelleborg Automoor

\section{PROBLEM ANALYSIS}

An active development of calculating machines, computer technologies and cyber-physical systems allows us to look at the existing application problems in the field of the routine [3-6]. It causes the creation of new opportunities which we wouldn't be able to use if we didn't have computer systems. Appliance of cloud computing (when processing a big amount of data from the distributed systems) simplifies the maintenance of information systems and creates new services. Therefore, it leads to a company's decrease of operational outlay [710].

The administration of ports Moerdijk and Rotterdam (Netherlands) is also interested in mooring time minimization. It leads to decrease in financial spending for the petrol, saves the ecology and optimizes the employee's job.

There was a task to explore the options of mooring process time. Optimization didn't provide the reconstruction of the port as well as blocking its job. The opportunity to lay the engineering networks on the territory of the berth was also excluded. It was planned to create an informational system which would inform about the loading of the pier in real time mode. Moreover, it will provide the information about the distance between the pier and a ship. The Marine Pilots need this information during the mooring process. As a result, it eliminates the human factor and makes it easier and faster to moor a ship. An important note is also the installation and dismantling, the cost of the system.

\section{IMPLEMENTATION}

The deadlines for implementation are quite short, and there is also no possibility of ongoing stay in the port. For the successful implementation it is important to get information on how to identify the ship and the distance to it. There is a need for data, using the standalone sensors of which would be possible to analyze and to predict the system operation processes.

It is also important to take into account the system's operating conditions: it is the pier, the sea water, all four seasons.

- The first step in implementing the system is to use several sensor units with a large number of different sensors, and with inefficient use of energy but with receiving any kind of data.

- The second step is supposed to be reducing the number of sensors, optimizing the power consumption, collecting data from the bigger number of sensor units.

- The third step is supposed to be an invention of an energy-efficient unit, with a limited number of sensors but with the ability to transmit data in real time and with significant long battery life.

The primary task was to monitor the situation with various autonomous sensors for the future effectiveness analysis of each sensor.

At this stage, there is no connection between the system units. Receiving the data proceeds when we detach a sensor unit and receive the data through the RJ45 Interface, while charging the battery pack.

Sensor units are supposed to work 10-14 days in ports Moerdijk and Rotterdam. Since the sensor units are located on the Baffle Systems at the sea berth, it is 
important to organize its convenient installation and dismantling. There is also a need for minimizing its time because at this time the pier is standing by.

The most complicated part was to actualize the sensor unit's position in Moerdijk, since its Baffle System is compacted enough (Fig. 5, 6) and our sensor unit has significant dimensions (its battery can work autonomously up to 14 days). We decided to divide our sensor unit into 2 parts: directly the part with sensors and the part with a computer and the battery.

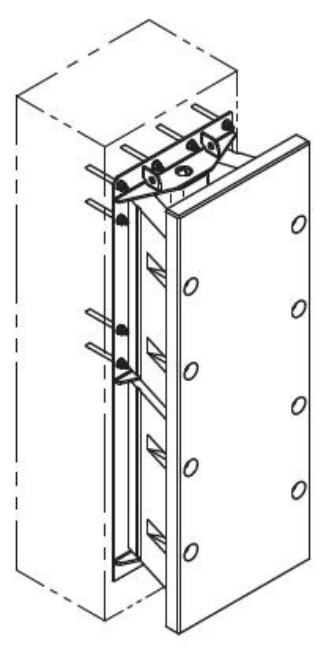

$a$

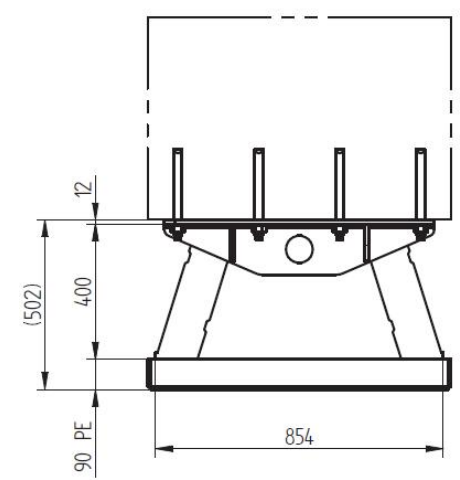

$b$
Fig 5. Moerdijk Baffle System. A schematic image: $a$-sideways; $b$-from above

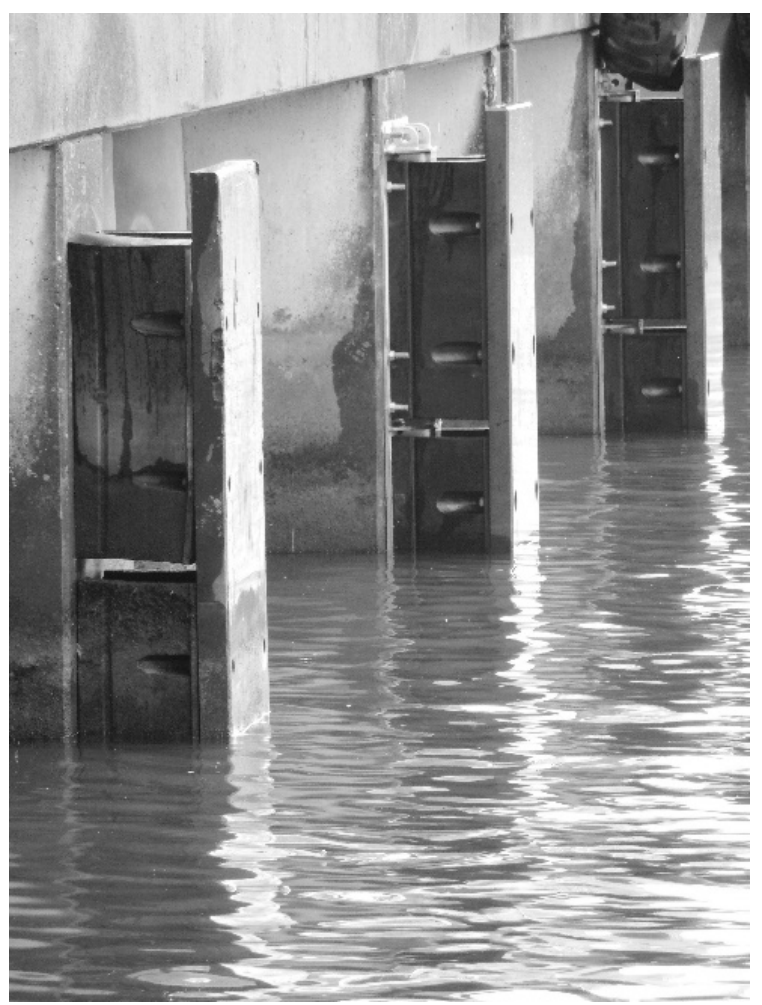

Fig. 6. Moerdijk Baffle System. Port Photo
For the first stage the structure of the autonomous unit was made according to the expected demands (Fig. 7). Between main units it is possible to distinguish the following:

- To find the distance between the pier and the ship is decided to use an Ultrasonic Distance Sensor.

- An Industrial Computer was used for the primary processing and saving the data flow.

- Sighting the ship is decided to organize using a magnetometer.

- A wave oscillation and last mooring phases were decided to analyze using an accelerometer and a gyroscope.

- Since it is a system made of multiple sensors with the one data flow, to synchronize them and to process correctly there is a need for GPS coordinates and some time.

When choosing an ultrasonic sensor, it is important to have a convenient way to connect it and get results in addition to Moisture Protection parameters.

There was chosen a module of JSN-SR04T sensor, which is a waterproof module with a measuring range up to 5 meters and with a resolution of $1 \mathrm{~cm}$. The module is supplied with a signal preprocessing board and the connection method through the UART Interface.

Since this module belongs to the budgetary sensors, libraries to work with it are ported to major platforms.

The selection of accelerometer sensors, magnetometer and gyroscope is the most important part because these sensors will provide the main flow of sensory information.

Among different ready-made sensors we agreed on the Xsense Mti-3 Module. The choice of this sensor is due to the integration of 3D Gyroscope, 3D Accelerometer and 3D Magnetometer and a Thermometer in one module. At the same time this module performs preliminary processing and correction of the results taking into account temperature drift. The module is also characterized by stability and quality of results.

The connection is occurring via the UART Interface. The existence of the software for its operation and configuration is the biggest advantage.

Using a full-fledged computer is inefficient in terms of electricity use but it was a critical time to implement the first version of the system and the ability to quickly change the number and type of sensors and, moreover, a software to work with them.

The computer for data storage and sensor processing was selected on the basis of the NI-Z8350UL Motherboard (Fig. 9) [11].

This choice was justified by low power consumption and compacted form-factor $(10 \mathrm{~mm} * 72 \mathrm{~mm})$. The cooling process occurs using a passive radiator and with the absence of moving parts. This increases the reliability and durability of the device. There is an Intel Cherry Trail Atom Z8350 CPU processor, 2 Gb of RAM and flash memory devices. It is more than enough for the system operation. 


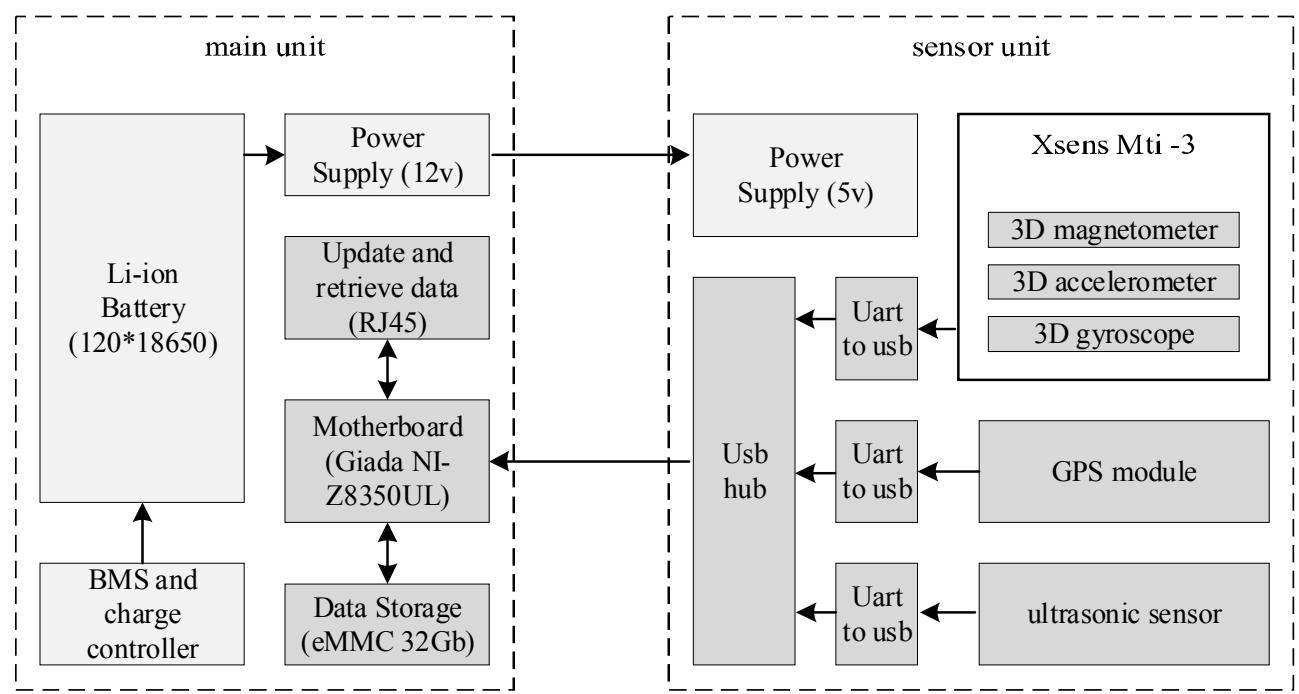

Fig. 7. The structure of the implemented system unit

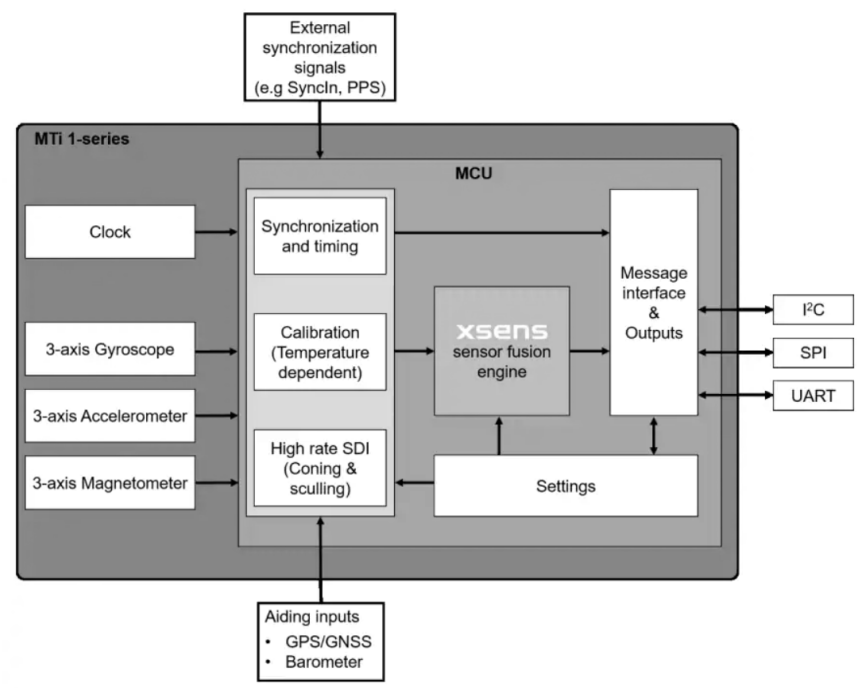

Fig. 8. The structure of the Xsense Mti-3

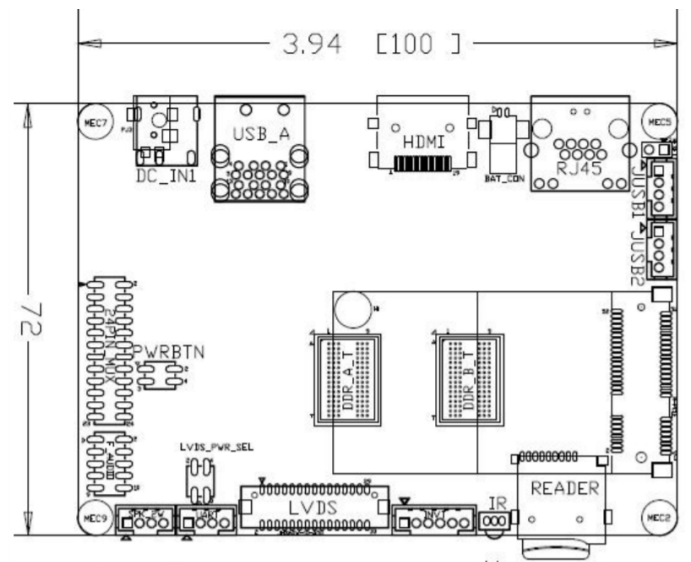

$a$

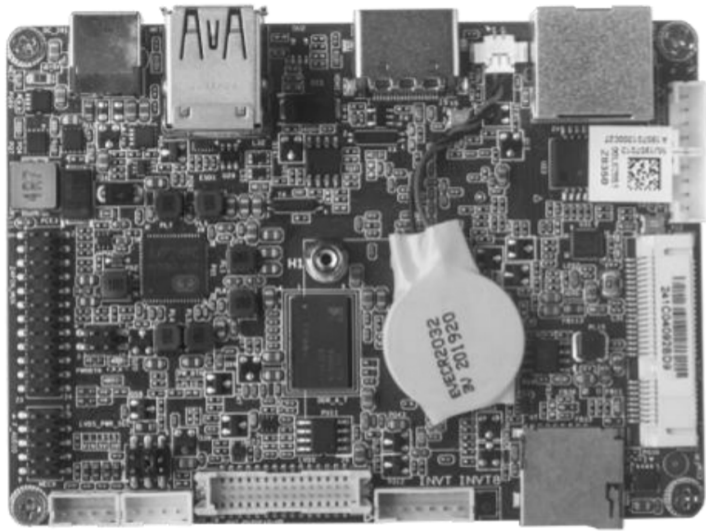

Fig. 9. Motherboard Giada NI-Z8350UL. $a$ - a schematic image, $b-a$ photo 
At the top of the sensor unit there is a module's antenna and the GPS module itself. It helps AT commands to be transmitted via the UART Interface.

The GPS Module is not needed for receiving the coordinates but for getting the accurate time so the data sets from the sensors have an exact timestamp.

Processing the data from the several sensor units, data synchronization will occur exactly by timestamps. The GPS module does not work constantly, because it consumes a lot of energy, it is turned on several times a day to adjust the clock that is located on the motherboard.

A printed circuit board was invented for the sensor part (Fig. 10), where we located all sensors, interface converters, USB Hub and power supply circuits of each of the PCB parts.

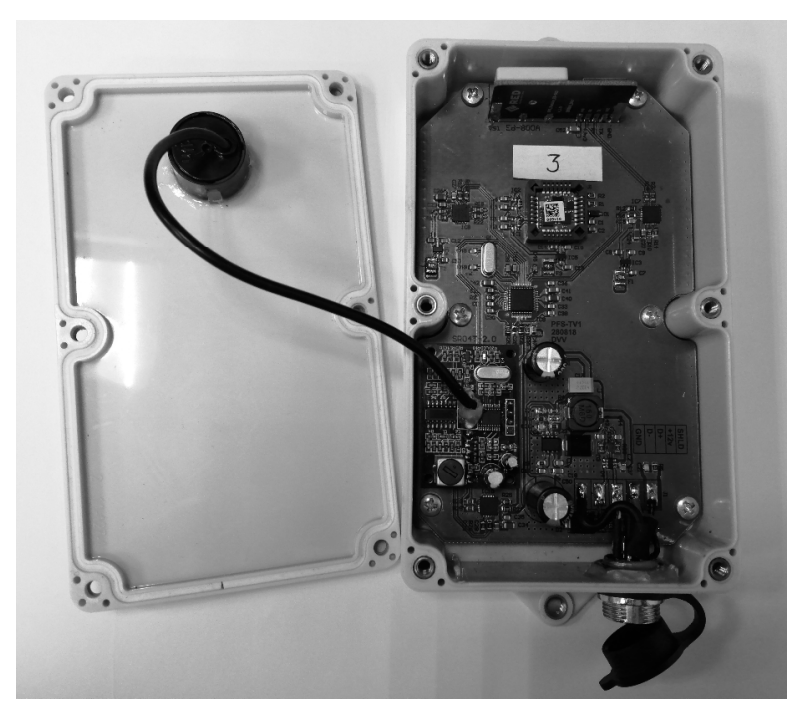

Fig. 10. A Sensor measurement unit

On the motherboard there was installed a Linux Mint 32-bit operating system, with no graphic interface and optimized for energy efficient work. The software for collecting sensory information is created in a Python environment.

For receiving the maximum amount of information, the frequency of sensor polling was as high as possible and limited by the capabilities of the sensor itself. For example, the magnetometer outputs data with a frequency of $1 \mathrm{~Hz}$ and an accelerometer with a frequency of $200 \mathrm{~Hz}$. The sensor unit has archived around $1,5 \mathrm{~Gb}$ of data during the day.

According to preliminary estimates, about $1,5 \mathrm{~kW}$ of electricity was required for continuous operation of the sensor unit for 10-14 days. It means that the main device's volume will be occupied by the battery. In Moerdijk's Baffle System (Fig.5) there is a technological hole inside. It is used for the sensor unit's battery location.

The Baffle System in Rotterdam port is huge Fig. 14) and there is no need for a complicated battery corpus, but to maintain compatibility and interchangeability it was agreed on making both battery units the same.

The battery was assembled from $120 \mathrm{Li}$-on 18650 cells and with a capacity of $3100 \mathrm{mAh}$. The preference of these elements is well-grounded by their size and by the opportunity to collect on their basis the battery module. A case of the battery part (Fig. 11) is made of SAE 304 stainless steel and it is airtight because it will have an instant contact with the seawater during the water inflow.

The sensor part's case is made of stainless steel, easily removable binding and airtight plastic case (Fig. $10,11)$. There was chosen a plastic case of the sensor unit because it is important to ensure the magnetometer and the GPS Module are working.
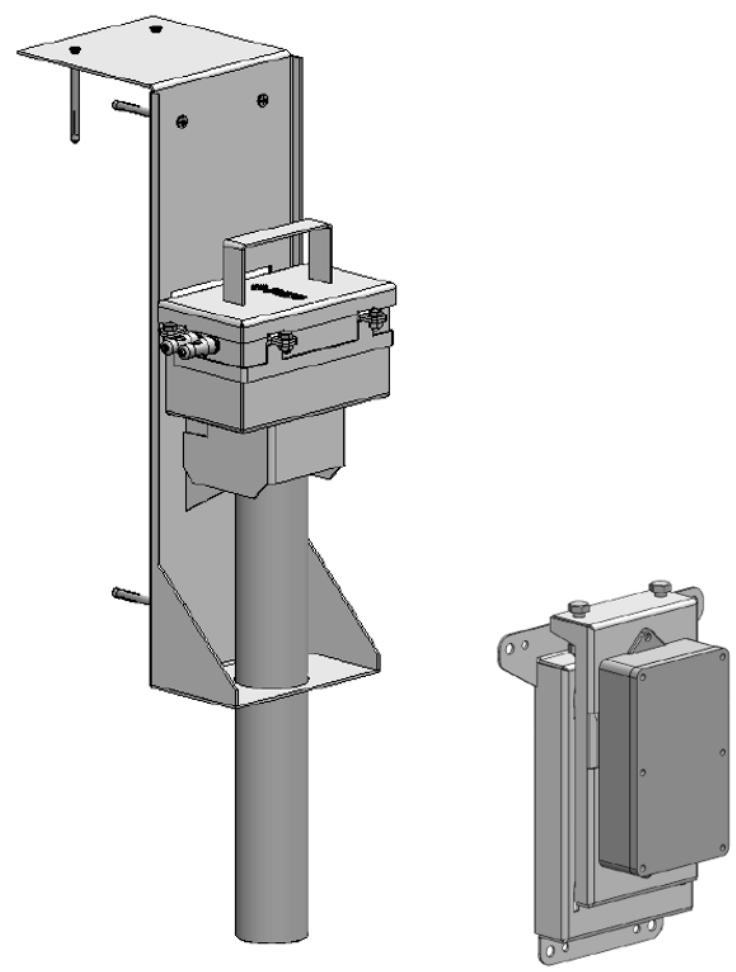

Fig 11. The battery and sensor part of the system's measuring unit

On the first stage it was decided to install 3 system's sensor units. They were originally built up in Moerdijk port (Fig. 12,13).

The battery part was planned on being located in the technological hole and the sensor part was attached to the Silicone Baffle Mechanism. The length of the cable from the battery part to the sensor unit is about 50 $\mathrm{cm}$. The distance between the sensor nodes is 15 meters. It is enough to cover the 50-60 meters ship.After the continuous system's work, for 10 days in Moerdijk the sensor units were dismantled, the batteries were charged and the sensor data was received. A preliminary technical inspection inside the sensor and battery system 
was conducted. The next step was to install sensor units in Rotterdam Port. Installation took place into the specially mounted brackets (Fig. 11). These brackets are important because The Baffle System in both ports is not similar. The Rotterdam's Baffle Mechanisms are big and massive (Fig. 14, 15). The distance between the battery and sensor systems is around 3 meters. The cable which connects the sensor and battery systems passed through a massive circuit (Fig.15). Of course, it didn't add reliability but it was enough for system to work 10-14 days to receive a data from the sensor units. The distance between the sensor nodes was around 25 meters. It was also enough to cover the ship of 50-60 meters.

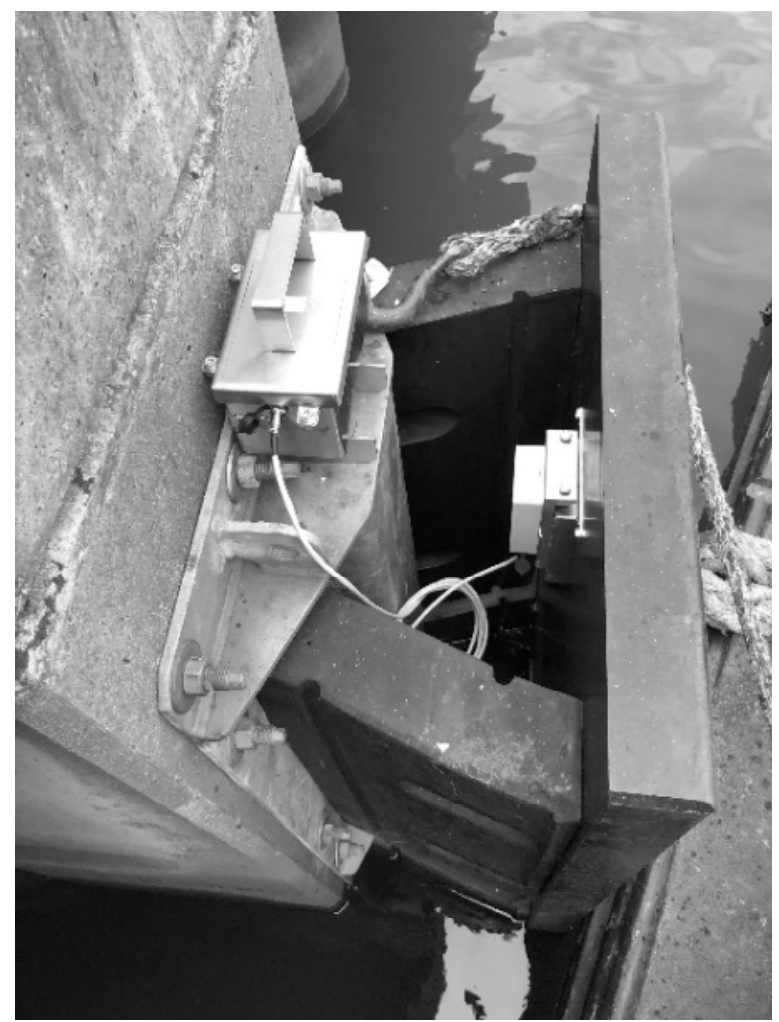

Fig. 12. The System, installed on the Baffle System in Moerdijk. From above

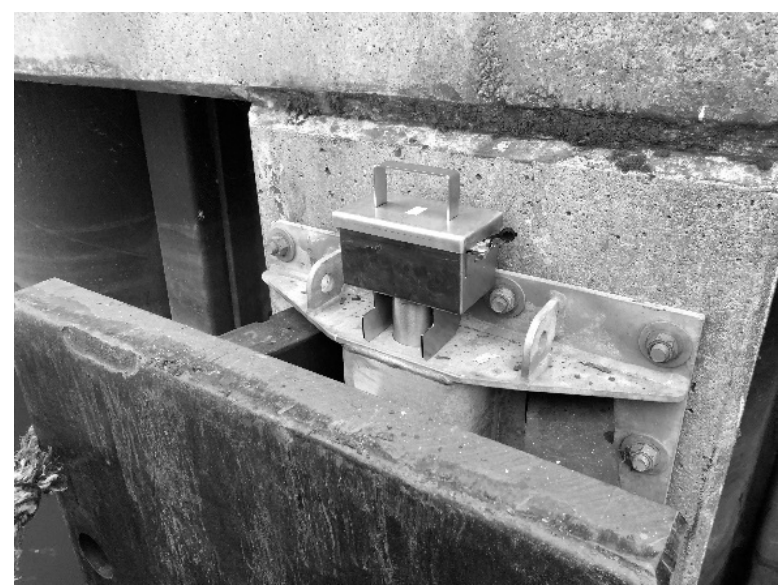

Fig. 13. The System, installed on the Baffle System in Moerdijk. Sideways
The Rotterdam's Baffle System peculiarity is that our Sensor Module is no longer attached to the rubber base but to the metal sheet which makes the magnetometer's work even more complicated.

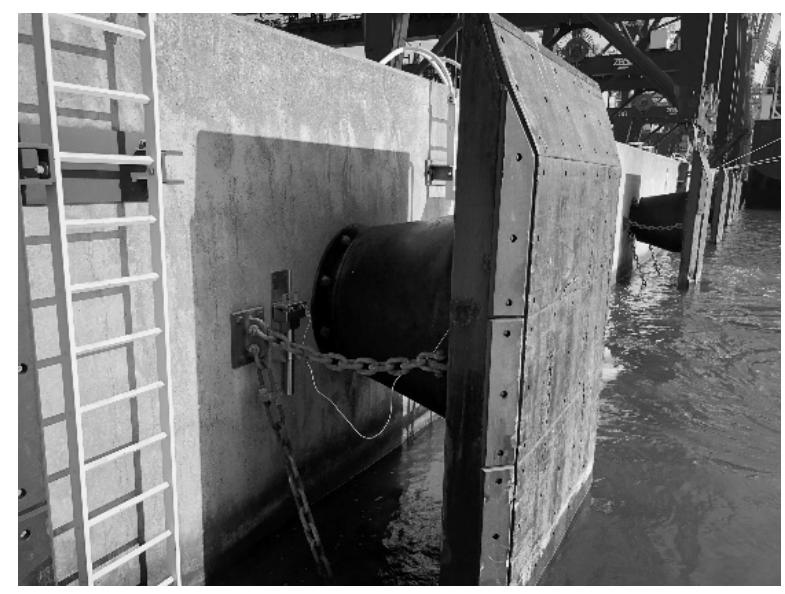

Fig. 14. The System, installed on the Baffle System in Rotterdam. Sideways

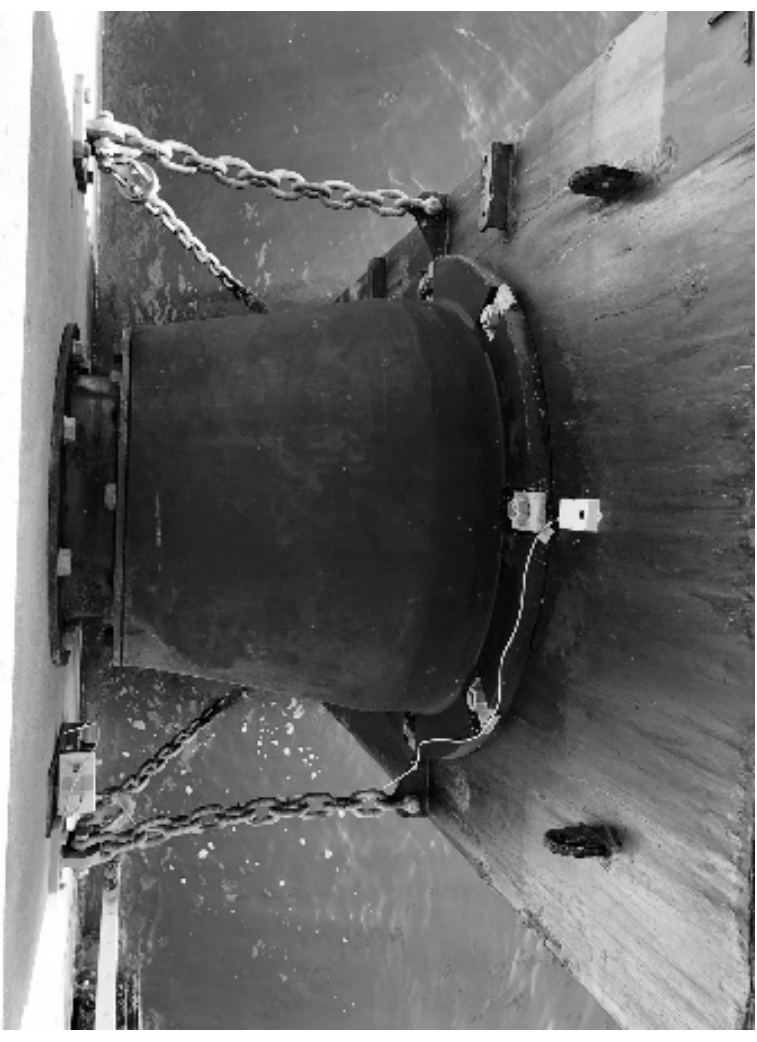

Fig. 15. The System, installed on the Baffle System in Rotterdam. From above

\section{CONCLUSION}

Mooring the ship is a complicated and often repetitive operation, in loaded ports there is a need to optimize this procedure. It was decided to create the Informational System to assist in the mooring process. This article is given to discuss the first iteration of this system. There was analyzed the set of the required 
components, including: an ultrasonic sensor for determining the distance to the ship, a magnetometer for detecting the ship, an accelerometer and a gyroscope to record the number of wave oscillation and the last mooring stage, the GPS Module for obtaining timestamps while saving sensory data. The computing module is an Industrial Motherboard with a compact form factor. The battery module provides a convenient installation and dismantling from the Baffle System with 10-14 days of autonomous work. There were 3 prototypes of measuring units implemented. They were installed in Moerdijk and Rotterdam ports. After having worked out a required period using the sensor units, we got data for the future analysis. There was found information about the sensor unit's technical disadvantages. This information will help us analyze the structure and model for the next step of the cyber-physical system to help moor a ship.

\section{REFERENCES}

[1] "MANDATORY RESOLUTIONS on the seaport of Mariupol", Notice to Mariners, Edition No 33, Notice No 362-378, Sep 2, 2016. Available: http://www.charts.gov. ua/viewer/web/ viewer. html?file=/ntm/ 2016/ ntm33(362378).pdf(In Ukrainian).

[2]Trelleborg Marine AutoMoor. [Online]. Available: https:// www.trelleborg.com/en/marine-and-infrastructure/automoor

[3] Grebeniak A., Miyushkovych E., Paramud Y. Digital interfaces in cyber-physical systems. Advances in CyberPhysical Systems. Volume 2, Number 1, 2017, pp. 6-10.

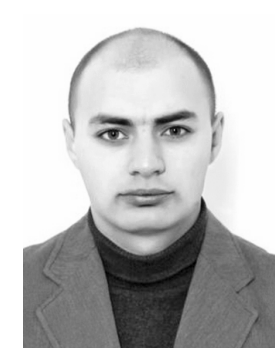

Andrii Grebeniak was born in 1986. He received the B.S. and M.S. degrees in Computer Engineering at Lviv Polytechnic National University in 2008/2009. From 2012 to 2018 , he was an assistant at the Computer Engineering Department of Institute of Com-
[4] A. O. Melnyk, D. V. Lykhotop, A. V. Grebeniak, "Embedded local Wi-Fi computer network with configuration using bluetooth technology", Journal “Computer systems and networks", Lviv, Ukraine, 2017, Issue 881, pp. 66-87. (In Ukrainian).

[5] D. V. Lykhotop, A.V. Grebeniak, "Basic approaches to designing the structures of embedded systems", 8-th International Joint Youth Science Forum «litteris Et Artibus» \& 13-th International Conference «Young Scientists Towards the Challenges of Modern Technology», Lviv, Ukraine, November 22-24, 2018, pp. 999-999. (In Ukrainian).

[6] Grebeniak A.V., Golembo V.A.. Chotyryrivneva arkhitektura avtonomnoho mobilnoho ahenta dlya detsentralizovanoho samoorhanizovanoho kolektyvu. [Four level architecture autonomous mobile agent for decentralized self-organized collective.]. Naukovyy visnyk Chernivetskoho universytetu "Kompyuterni systemy ta komponenty". Chernivtsi, Ukraine, 2015, vol. 6.1, pp. 86-92 (In Ukrainian).

[7] Derhamy, H. Architectural Design Principles For Industrial Internet of ThingsLule a, Sweden , 18. C. 285.

[8] Lea, P. Internet of Things for architects: architecting IoT solutions by implementing sensors, communication infrastructure, edge computing, analytics, and security: Packt Publishing, 2018. 524c.

[9] Lee, E. A., Seshia, S. A. Introduction to Embedded Systems, A Cyber-Physical Systems Approach: MIT Press, 2017. 568c.

[10] Kranz, M. Building the Internet of Things Implement New Business Models, Disrupt Competitors, Transform Your Industry: Wiley, 2016. 272c.

[11] Giada Embedded Motherboard. [Online]. Available: http://www.giadatech.com/index/product/detail/aid/235.html

puter Technologies, Automation and Metrology (ICTA). Since 2018 and till now, he has been a senior lecturer with the Computer Engineering Department. He has about 14 publications, including articles and participation in conferences, as well as the author of three patents. His research interests include autonomous decentralized measuring computer systems, theory of collective behavior of intelligent systems, multiagent systems. 